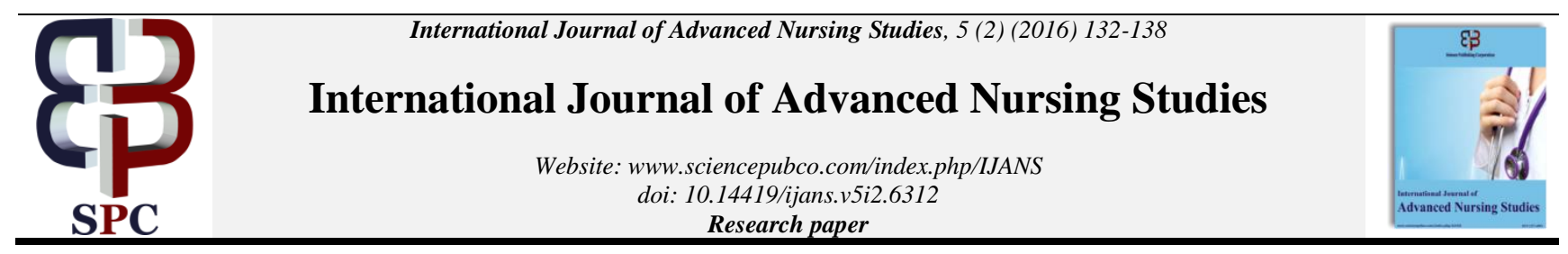

\title{
Awareness among glaucoma patient at upper Egypt
}

\author{
Magda A. M. Mansour ${ }^{1}$, Nermeen Mahmoud Abd-Elaziz ${ }^{* 2}$, Mimi M. Mekkawy ${ }^{3}$, Rania M. Ahmed ${ }^{4}$ \\ ${ }^{1}$ Assistant professor of Adult Nursing Department, Faculty of Nursing, Assuit University \\ ${ }^{2}$ Lecturer of Gerontological Nursing Department, Faculty of Nursing, Assiut University \\ ${ }^{3}$ Professor of Adult Nursing Department, Faculty of Nursing, Assuit University \\ ${ }^{4}$ Assistant professor of Radiological Science Department, College of Applied Medical Science-Taif University \\ *Corresponding author E-mail: nermeenbarakat@aun.edu.eg
}

\begin{abstract}
Aim: To assess the awareness among glaucoma patients at Upper Egypt Governorate hospitals.

Research design: Descriptive cross sectional research design was used in this study

Setting: The study was conducted in ophthalmology outpatient clinics (male \& female) at Assiut University Hospital \& Al-rmad Hospital, Elmina and Sohag Governorate.

Subjects: The sample of this study total coverage of glaucoma patients included (1000), the researcher taking the sample during one year, this sample aged 50 years and above.

Tool of study: One tool was used in this study include three parts, part I: patient demographic characteristics, part II: medical data, part III: knowledge about risk factors and self-practice regard glaucoma.

Results: The most of patients age ranged between 60:80 year, nearly three quarter $(74.6 \%)$ of them were females, and $80 \%$ of them comes from urban areas. The majority of studied sample (84.5\%) unaware about glaucoma disease and show statistical significant difference between awareness of them and their education, $\mathrm{P} \leq 0.05$. Also, there was no significant difference between knowledge of studied sample and their residence.

Conclusion: The majority of glaucoma patients complain from poor of knowledge \& practice.

Recommendation: Design \& implement of health educational program about glaucoma are needed to improve patient knowledge \& practice regard glaucoma.
\end{abstract}

Keywords: Glaucoma; Awareness; Intraocular Pressure (IOP); Blindness; Optic Nerve; Risk Factor.

\section{Introduction}

Glaucoma is a complex group of ocular disorders where different underlying abnormalities of the anatomic relations in the anterior segment of the eye. Glaucoma is the second most prevalent cause of vision loss worldwide. Specifically, it has been estimated that 6.5 million people was diagnosed with glaucoma by 2010 (Quigley 2006, Pascolini, 2012). The main modifiable risk factor for glaucomatous optic neuropathy is increased intraocular pressure (IOP) (National Institute for Health and Care Excellence, 2009). Although there are many possible causes of glaucoma (e.g. trauma, inflammation, previous surgery, or an inherited tendency), it is usually possible to identify the mechanism of elevated IOP by careful history taking, anterior segment examination, and optic disc assessment using a slit lamp (Philippin et al. 2012).

After assessment, the clinician can group the glaucomatous optic neuropathies into three main categories: primary open-angle glaucoma (POAG), primary angle-closure glaucoma (ACG), and secondary glaucoma's (including pseudo- exfoliation, pigmentary, uveitic, lens- induced, neovascular, steroid-induced and traumatic) (Bourne 2006). Africa, Japan, and Latin America have been shown to have higher rates of primary open angle glaucoma (POAG) than patients in China or India. Moreover, a study by Tajimi (2004) reported that patients with POAG and intraocular pressure (IOP) under $21 \mathrm{mmHg}$ were more common than other types of patients in Japan. Although prevalence rates of glaucoma in Korea have been reported to range from $2.04 \%$ to $4.7 \%$ (Hong et al. 1987 Choe 1993 and Iwase 2004).

A systematic review of World Health Organization (WHO) surveys on blindness and low vision in 2002 showed that there are 37 million blind people worldwide, with $12.3 \%$ (4.4 million) attributable to glaucoma, second only to cataract $(48 \%)$. Quigley et al. 2006 predicted that 8.4 million people will be blind as a result of primary glaucoma by 2010 , rising to 11.1 million by 2020 . The number of individuals who are blind is a fraction of those suffering from the disease; the authors estimated that the number of people with primary glaucoma as will be 60.5 million by 2010 , increasing by 20 million over the subsequent decade (Faal, 2012). It has been seen from various population -based studies that the awareness and knowledge of glaucoma among both rural and urban population is remarkably low, especially in developing countries .which has negative impact on health seeking behavior. Given that the outreach of the health, care system in developing countries remain far from optimal. It is essential that each of the health care providers be educated about glaucoma so as to reach a large sector of the population, which does not have access to a comprehensive eye care center (Neuberger, 2000).

A nursing-based educational programme can address these issues by improving patients' awareness about their illness and hence compliance with therapy, as well as encouraging natural approaches to glaucoma care (Tsai \&Dawn, 2007). Patients' expectations have begun to play an increasingly important role in medical and nursing care and quality assessment. Patients with glaucoma 
were shown to have various expectations depending on their age, socioeconomic status and severity of their conditions (Marion, 2007).

Risk factor of glaucoma as increased Intraocular Pressure (IOP), age everyone over age 40 year is at risk of developing glaucoma family history, chronic diseases as diabetes, migraine, high blood pressure, conditions use of steroid for prolonged periods of time and previous eye surgery also puts people at risk (Glaucoma research foundation (2012).

The prevalence of glaucoma in East, Central and Southern Africa can be conservatively estimated to be 10,000 people for every 1 million population which may be higher in West Africa. Glaucoma in Nigeria is the second most common cause of blindness after cataract and approximately 980,000 Nigerians are blind from glaucoma (Cook 2009).

Glaucoma was the cause of acquired blindness in $12.1 \%$ of cases in Mansora. Similarly, glaucoma was the cause of blindness in $19.7 \%$ of cases in a study in Alexandria, $7.6 \%$ in the Elazhar University Study, and $9.2 \%$ in Shibin ElKom by El Gilany et al. $2012^{[16]}$ asserted that health insurance was the source of healthcare for more than $80 \%$ of participants, whereas $13.3 \%$ received free service. On the other hand, all patients recruited into our study were receiving free service. Fraser et al, 2011 Showed that deprivation is associated with the presentation of advanced glaucomatous optic neuropathy to hospital clinics, which represents an important risk factor for blindness from glaucoma.

Assiut University Hospital (AUH) is a tertiary medical centre in Assiut the most populous governorate of Upper Egypt which serves a large number of Egyptians from all over Upper Egypt. Egypt is one of the most populous countries in Africa and the Middle East, with a population approaching 80 million. (Altangerel, 2009). According to the Egyptian Society for glaucoma disease. Incidence of glaucoma in Egypt about $0.5 \%$ to $1 \%$ of the total population. In Egypt, more than half a million children and adolescents are estimated to be affected by glaucoma (Egyptian Society for glaucoma disease, 2011).

\subsection{Operational definitions}

Awareness of glaucoma was defined as having heard of glaucoma. Knowledge was defined as having some correct understanding of the disease (Onabolu, 2014).

Risk factors: describes features that may be causal in disease, as they are statistically associated with the disease, and were (or could have been) present before its occurrence, and could conceivably have played an essential role along with other factors in incident disease. We could call them causes (Gordon, 2002).

\subsection{Significant of the study}

Glaucoma is a major public health problem and is one of the leading causes of blindness worldwide. Most of the patients present late for medical attention when the eye condition is already advanced which may be due to lack of knowledge about glaucoma and because most cases are asymptomatic, many affected individuals are unaware that they have the disease leading to avoidable blindness (Onunkwor, 2012). This is the first report that evaluates the 'glaucoma awareness' among Egyptian glaucoma patients. Regional studies in Egypt have evaluated glaucoma as a cause of blindness. No regional reports have described the awareness glaucoma patients. No studies were conducted to address glaucoma patients awareness aged 50 years and over at Upper Egypt Governorate.

\subsection{Aim of the study}

To assess the awareness among glaucoma patients at Upper Egypt Governorate Hospitals.

\section{Subjects and method}

\subsection{Research design}

Descriptive cross sectional research design was used in this study.

\subsection{Setting}

The study was conducted in ophthalmology outpatient clinics (male \& female) at Assiut University Hospital \& Elramad hospital Ministry of Health at Assiut Governorate, Elmina University Hospital and Sohag University Hospital.

\subsection{Subjects}

The sample of this study total coverage of glaucoma patients included (1000), the researchers taking the sample starting from June 2014 to May 2015, this sample aged 50 years and above, intraocular pressure $\leq 21 \mathrm{mmHg}$, characteristic pattern of glaucomatous visual field changes and previous diseases such as type 1 and 2 diabetes mellitus and patients who agree to participate in the study. The sample size was determined based on epi info program using $10 \%$ acceptable error, $95 \%$ confidence coefficient.

\subsection{Tool of the study}

Structure interview questionnaire was developed based on the relevant literature and included the following three parts:

- First part: used to collect information about patient demographic characteristics including age, sex, marital status, educational, occupation and residence.

- Second part: to assess medical data includes history of glaucoma, family history, smoking and complain of chronic illness.

- Third part: this part include questions about glaucoma was used to knowledge abut glaucoma, risk factors and selfpractice regard glaucoma such as you known glaucoma, causes, symptoms, types, glaucoma lead to blindness in the eye, early treatment can prevent complication.

- Questions about risk factors as is there a relationship between the hypertension and glaucoma, does the age of the causes of glaucoma, considered genetics, is there a relationship between myopia and glaucoma, is there a relationship between diabetes and glaucoma, is there a relationship between contraception and glaucoma, is there a relationship between excessive drinking coffee and glaucoma, is excessive use computer leads to glaucoma.

- Questions about practice as are doing you excessive use computer, excessive drinking coffee and regularly sight measure IOP periodically, what you are doing in the case of the appearance of symptoms of glaucoma.

\subsection{Methods of data collection included}

i) A written permission to carry out the study was obtained from the directors of each hospital to collect the necessary data after explanation of the aim present study. The period of data collection was about one year from (June 2014 to May 2015). Interview by the prepared sheet to assess awareness and practice, each patient was interviewed individually, the questionnaires were filled by the researcher who was asking the patient \& documenting their answer \& the sheet was filled \& completed in 25 minutes.

Validation of tool was assessed before data collection, jury composed of 5 experts in medicine, research and nursing field revised the content of validity to ascertain the appropriateness of items for measuring what they are supposed to measure.

iii) Tool reliability: the researchers applied it to a pilot study was conducted to evaluate the validity and reliability of the 
tool. It was carried out on $10 \% 100$ patients suffering from glaucoma disease drawn from the previous settings. These patients were excluded from the actual sample. Also the pilot study was done to evaluate the applicability and clarity of the tool. Accordingly, the necessary modifications were done. The reliability test was calculated using correlation coefficient and it was 0.89 which is appropriate for conducting such a study.

iv) Ethical consideration: Research proposal were approved from Ethical Committee in the Faculty of Nursing. There is no risk for study subject during application of research. Written consent was obtained from patients or guidance that is willing to participate in the study, after explaining the nature and purpose the study. Confidentiality and anonymity were assured. Study subject have the right to refuse to participate or withdraw from the study at any time.

v) Statistical Analysis: Data entry and statistical analysis were done using SPSS 20.0 statistical software packages. Data were presented using descriptive statistics in the form of frequencies and percentages for qualitative variables, and means and standard deviations, the relationship between awareness of glaucoma and demographic characteristic such as age, sex, level of education and occupation, was assesses using chi-square test, a two-tailed p-value of less than 0.05 was considered statistically significant.

\section{Results}

Table 1: Represented that most of participant age ranged between $60-80$ yrs $(74.6 \% \mathrm{n}=746)$ with mean age $62.47 \pm 5.32$, female patients represent $56.2 \%$, while male patients represent $43.8 \%$, but $60.2 \% \mathrm{n}=602$ comes from urban area and $70.0 \%$ of them were married. Regard level of education $36.8 \% \mathrm{n}=368$ are primary school follow by secondary school $(30.2 \% \mathrm{n}=302)$. As regard occupation $68.8 \%$ of them were not worked and more than half of them $(53.5 \% \mathrm{n}=535)$ from Assiut Governorate.

Table 2: Showed that $69.4 \%$ of participants do not smoke, while $73 \%$ of the studied sample no family history for glaucoma and $37 \%$ complain from heart diseases.

Table 3: Showed that $72.8 \%$ of participants had no answer about causes of glaucoma, $17.6 \%$ of them say I don't know regarding to symptoms of glaucoma, while more than half of them $57.4 \%$ had no answer about glaucoma lead to blindness while only $9.2 \%$ say yes about early diagnosis and treatment prevents complications of glaucoma. And $69.6 \%$ say I don't know regarding to diagnosis is not done without general anesthetic for measuring eye pressure and examination of the fundus.

Table 4: Illustrated that knowledge of patient regard risk factor of glaucoma, more than half of the studied sample $(53.2 \%)$ had no relationship between the hypertension and glaucoma, $73 \%$ of them say I don't know about age is a risk factor for glaucoma, while regarding to relationship between contraception and glaucoma, but only $7.8 \%$ of patients say yes and $2.4 \%$ of the had yes answer about healthy diet protects against glaucoma.

Table 5: Represented that most of participant answer no regard self-practice about glaucoma.

Table 6: Demonstrated that there statistical significant difference between level of education and awareness of glaucoma $(\mathrm{P}<0.001 *)$, while no statistical significant difference between awareness of glaucoma and age, sex and occupation.

Figure (1): Illustrated that $15.5 \%$ of the patients aware about glaucoma and $84.5 \%$ of them unaware about glaucoma.

Table 1: Demographic Characteristics for Patient Participant in Study N=1000

\begin{tabular}{|c|c|c|}
\hline Demographic data & N. (1000) & $\%$ \\
\hline \multicolumn{3}{|l|}{ Age (years): } \\
\hline - $50-<60$ & 254 & 25.4 \\
\hline - $\quad 60-80$ & 746 & 74.6 \\
\hline Mean \pm S.D & $62.47 \pm 5.32$ & \\
\hline \multicolumn{3}{|l|}{ Gender: } \\
\hline - Male & 438 & 43.8 \\
\hline - Female & 562 & 56.2 \\
\hline \multicolumn{3}{|l|}{ Residence: } \\
\hline - Urban & 602 & 60.2 \\
\hline - $\quad$ Rural & 398 & 39.8 \\
\hline \multicolumn{3}{|l|}{ Marital status: } \\
\hline - $\quad$ Single & 146 & 14.6 \\
\hline - $\quad$ Married & 700 & 70.0 \\
\hline - Widow & 154 & 15.4 \\
\hline \multicolumn{3}{|l|}{ Level of Education: } \\
\hline - $\quad$ Read and write & 176 & 17.6 \\
\hline - $\quad$ Primary school & 368 & 36.8 \\
\hline - $\quad$ Secondary & 302 & 30.2 \\
\hline - University & 154 & 15.4 \\
\hline \multicolumn{3}{|l|}{ Occupation: } \\
\hline - Worked & 312 & 31.2 \\
\hline - $\quad$ Not worked & 688 & 68.8 \\
\hline \multicolumn{3}{|l|}{ Governorate: } \\
\hline - $\quad$ Assiut & 535 & 53.5 \\
\hline - $\quad$ Elmenia & 252 & 25.2 \\
\hline - $\quad$ Sohag & 213 & 21.3 \\
\hline
\end{tabular}

Table 2: Distribution of Studied Sample According to Their Medical Data (N=1000)

\begin{tabular}{|c|c|c|}
\hline Medical Data & N. (1000) & $\%$ \\
\hline \multicolumn{3}{|l|}{ Smoking } \\
\hline - Yes & 306 & 30.6 \\
\hline - $\quad$ No & 694 & 69.4 \\
\hline \multicolumn{3}{|l|}{ Family History } \\
\hline - Yes & 270 & 27.0 \\
\hline - $\quad$ No & 730 & 73.0 \\
\hline \multicolumn{3}{|l|}{ Chronic illness } \\
\hline - $\quad$ No & 254 & 25.4 \\
\hline - Hypertension & 198 & 19.8 \\
\hline - Diabetes mellitus & 172 & 17.2 \\
\hline - $\quad$ Heart disease & 370 & 37.0 \\
\hline - $\quad$ Other & 6 & 0.6 \\
\hline
\end{tabular}


Table 3: Knowledge of Patient Regard Glaucoma N=1000

\begin{tabular}{|c|c|c|c|c|c|c|}
\hline \multirow{2}{*}{ Knowledge } & \multicolumn{2}{|l|}{ Yes } & \multicolumn{2}{|l|}{ No } & \multicolumn{2}{|c|}{ I don't know } \\
\hline & N. & $\%$ & N. & $\%$ & N. & $\%$ \\
\hline - $\quad$ Meaning of glaucoma & 72 & 7.2 & 706 & 70.6 & 222 & 22.2 \\
\hline - Causes of glaucoma & 116 & 11.6 & 728 & 72.8 & 156 & 15.6 \\
\hline - Symptoms of glaucoma & 84 & 8.4 & 740 & 74.0 & 176 & 17.6 \\
\hline - Types of glaucoma & 22 & 2.2 & 896 & 89.6 & 82 & 8.2 \\
\hline $\begin{array}{l}\text { - You know what you are doing in the case of the appear- } \\
\text { ance of symptoms }\end{array}$ & 74 & 7.4 & 606 & 60.6 & 320 & 32.0 \\
\hline - You notice white patches in the eye & 68 & 6.8 & 702 & 70.2 & 230 & 23.0 \\
\hline $\begin{array}{l}\text { - Early diagnosis and treatment prevents complications of } \\
\text { glaucoma }\end{array}$ & 92 & 9.2 & 502 & 50.2 & 406 & 40.6 \\
\hline - Diagnostic radiology useful in the diagnosis of glaucoma & 52 & 5.2 & 136 & 13.6 & 812 & 13.6 \\
\hline $\begin{array}{l}\text { - Using general anesthetic for measuring eye pressure and } \\
\text { examination of the fundus }\end{array}$ & 42 & 4.2 & 262 & 26.2 & 696 & 69.6 \\
\hline
\end{tabular}

\begin{tabular}{|c|c|c|c|c|c|c|}
\hline \multirow{2}{*}{ Risk factor } & \multicolumn{2}{|l|}{ Yes } & \multicolumn{2}{|l|}{ No } & \multicolumn{2}{|c|}{ I don't know } \\
\hline & N. & $\%$ & $\mathrm{~N}$. & $\%$ & N. & $\%$ \\
\hline - Is there a relationship between the hypertension and glaucoma & 110 & 11.0 & 532 & 53.2 & 358 & 35.8 \\
\hline - Is early diagnosis and treatment of blindness protects & 84 & 8.4 & 740 & 74.0 & 176 & 17.6 \\
\hline - $\quad$ Age is a risk factor for glaucoma & 92 & 9.2 & 178 & 17.8 & 730 & 73.0 \\
\hline - Genetics and inbreeding of reasons for glaucoma & 96 & 9.6 & 274 & 27.4 & 630 & 63.0 \\
\hline - There a relationship between myopia and glaucoma & 122 & 12.2 & 648 & 64.8 & 230 & 23.0 \\
\hline - There a relationship between diabetes and glaucoma & 82 & 8.2 & 460 & 46.0 & 458 & 45.8 \\
\hline - Is there a relationship between contraception and glaucoma & 78 & 7.8 & 374 & 37.4 & 548 & 54.8 \\
\hline - There a relationship between coffee and glaucoma & 98 & 9.8 & 350 & 35.0 & 552 & 55.2 \\
\hline - Excessive use computer leads to glaucoma & 100 & 10.0 & 208 & 20.8 & 692 & 69.2 \\
\hline - A healthy diet protects against glaucoma & 24 & 2.4 & 170 & 17.0 & 806 & 80.6 \\
\hline - The fundus eye examination periodically to prevent glaucoma & 40 & 4.0 & 284 & 28.4 & 676 & 67.6 \\
\hline - The regularly sight measure to prevent of glaucoma & 51 & 5.1 & 137 & 13.7 & 812 & 81.2 \\
\hline
\end{tabular}

Table 5: Patient Self-Care Practice Regard Glaucoma N=1000

\begin{tabular}{|c|c|c|c|c|}
\hline \multirow{2}{*}{ Self-care practice } & \multicolumn{2}{|l|}{ Yes } & \multicolumn{2}{|l|}{ No } \\
\hline & N. & $\%$ & N. & $\%$ \\
\hline - Do you regularly measuring vision careful & 42 & 4.2 & 958 & 95.8 \\
\hline - Do you drink coffee in large quantities during the day & 84 & 8.4 & 916 & 91.6 \\
\hline Are you taking healthy food properly?- & 114 & 11.4 & 886 & 88.6 \\
\hline - $\quad$ Are they performed testing periodically every six months or annually? & 132 & 13.2 & 868 & 86.8 \\
\hline - What you are doing in the case of the appearance of symptoms. & 74 & 7.4 & 606 & 60.6 \\
\hline
\end{tabular}

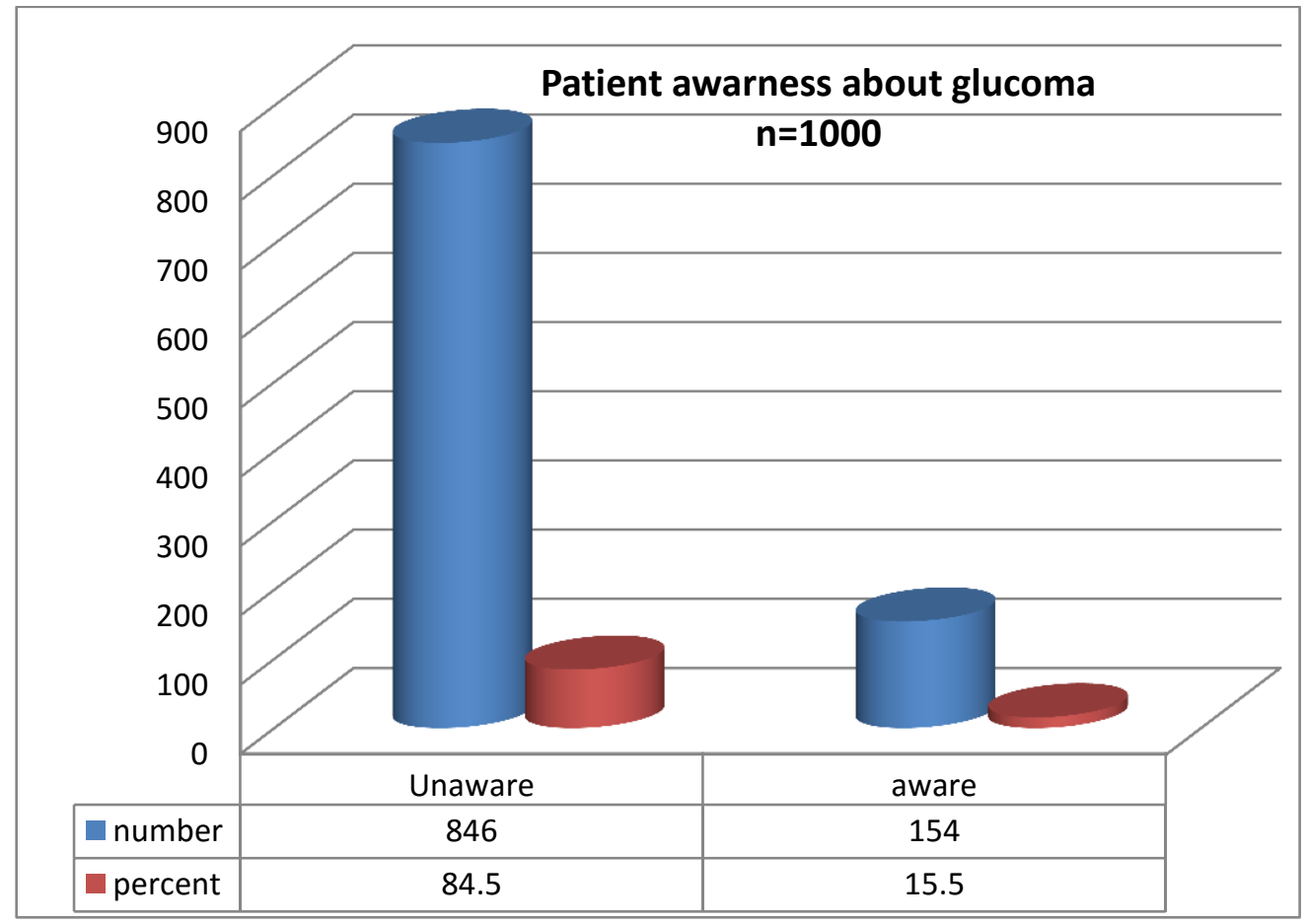

Fig. 1: Distribution of Studied Sample Awareness about Glaucoma N=1000. 
Table 6: Relation between Awareness of Glaucoma and Demographic Data

\begin{tabular}{|c|c|c|c|c|c|c|}
\hline demographic data & \multicolumn{2}{|c|}{$\begin{array}{l}\text { Awareness } \\
(n=154)\end{array}$} & \multicolumn{2}{|c|}{$\begin{array}{l}\text { Unawareness } \\
(\mathrm{n}=846)\end{array}$} & $X^{2}$ & (P-value) \\
\hline $\begin{array}{cc}\text { Age (years): } \\
\qquad \quad 50-<60 \\
-\quad 60-80\end{array}$ & $\begin{array}{l}38 \\
116\end{array}$ & $\begin{array}{l}15 \\
15.5\end{array}$ & $\begin{array}{l}216 \\
630\end{array}$ & $\begin{array}{l}85.0 \\
84.5\end{array}$ & 0.02 & $1.000 \mathrm{~ns}$ \\
\hline $\begin{array}{l}\text { Gender: } \\
\text { - } \quad \text { Male } \\
\text { - } \quad \text { Female }\end{array}$ & $\begin{array}{l}58 \\
96\end{array}$ & $\begin{array}{l}13.2 \\
17.1\end{array}$ & $\begin{array}{l}380 \\
466\end{array}$ & $\begin{array}{l}86.85 \\
82.9\end{array}$ & 1.39 & $\begin{array}{l}0.26 \\
\text { ns }\end{array}$ \\
\hline $\begin{array}{ll}\text { Level of Education: } \\
\text { - } & \text { Read and write } \\
\text { - } & \text { Primary school } \\
\text { - } & \text { Secondary } \\
\text { - } & \text { University }\end{array}$ & $\begin{array}{l}12 \\
48 \\
68 \\
26\end{array}$ & $\begin{array}{l}6.8 \\
13.0 \\
22.5 \\
16.9\end{array}$ & $\begin{array}{l}164 \\
320 \\
234 \\
128\end{array}$ & $\begin{array}{l}93.2 \\
87.0 \\
77.5 \\
83.1\end{array}$ & 11.7 & $0.001 *$ \\
\hline \begin{tabular}{ll}
\multicolumn{2}{c}{ Occupation: } \\
- & Worked \\
- & Not worked
\end{tabular} & $\begin{array}{l}66 \\
88\end{array}$ & $\begin{array}{l}13.2 \\
17.6\end{array}$ & $\begin{array}{l}434 \\
412\end{array}$ & $\begin{array}{l}86.8 \\
82.4\end{array}$ & 1.85 & $\begin{array}{l}0.10 \\
\text { ns }\end{array}$ \\
\hline
\end{tabular}

Ns No statistically significant difference $(\mathrm{p}>0.05) *$ significant difference $(\mathrm{p} \leq 0.05)$.

\section{Discussion}

Glaucoma is a term used to describe several types of eye conditions that result in optic nerve damage. In many cases, damage to the optic nerve is caused by abnormally increased pressure in the eye, a condition known as high intraocular pressure (IOP) or ocular hypertension (Cook 2009).

Glaucoma is the second leading cause of preventable blindness; it also is the leading cause of irreversible visual loss. By the year 2020 it is estimated that there will be almost 80 million people in the world with glaucoma. The majority of these individuals will have open-angle glaucoma OAG. Of those with OAG, 70\% will be women and $87 \%$ will be Asian. Bilateral blindness from glaucoma is projected to affect 11 million individuals worldwide by 2020 (Quigley 2006).

This study represent that most of participant age range between $60-80$ yrs. $(74.6 \% \mathrm{n}=746)$ with mean age $62.47 \pm 5.32$, as in glaucoma frequency increases greatly with age. This increase occurs because the drainage mechanism gradually may become clogged with aging, even though the drainage angle is open. As a consequence, the aqueous fluid does not drain from the eye properly. The pressure within the eye, therefore, builds up painlessly and without symptoms (Nilforushan et al. 2010, Debjit et al. 2012) Also, there is strong evidence that older age is an independent risk factor for the progression of ocular hypertension and glaucoma. Older age has been reported as a risk factor for the development of glaucoma in patients with ocular hypertension in multiple longitudinal studies Miglior et al. 2007, Grehn 2009 found that increasing age is a risk factor for the development of glaucoma.

Regard Sex : Females were more common to have glaucoma than male; more than half of studied sample were female, this agree with Nilforushan et al. 2010 reported that, Women are three times more likely than men to develop acute angle closure glaucoma due to their shallower anterior chambers, and disagree with Tenkir et al. 2010 who study Glaucoma awareness among people attending ophthalmic outreach services in Southwestern Ethiopia Ophthalmology and reported that Majority of the studied sample $(69.7 \%)$ were males.

According to marital status: More than two thirds of participants were married, these agree with Tenkir et al. 2010 who reported that $(95 \%)$ of the study group were married. These results agreed with Onunkwor 2012 who found that the majority of studied sample were married.

In this study according to the residence, the present study showed that less than three quarter of the studied sample were from urban while more than one fifth of the studied sample were from rural. Also, there was not significant difference between knowledge of the studied sample and their residence. That might be explained by the employees from the rural area were working in urban areas, and they have an easy access to eyes hospitals. These finding were disagreed with Krishnaiah, et al 2009 who carried out a study to assess population awareness about glaucoma in the rural area of
Southern India, and found that the people in rural area are less aware of the disease and have less knowledge about glaucoma than people living in urban areas.

In the current study it was observed that more than one third of them are primary school follow by secondary school. These results were similar to Subhratanu, et al. $2015^{[29]}$ who study awareness of glaucoma, and health beliefs of patients suffering primary acute angle closure and reported that glaucoma more common among primary school education. As regard occupation more than two third of them were not worked. This similar with current study explain that more than one third of participants had primary school education. This study agree with Subhratanu, et al. 2015 reported that, $42 \%$ were unemployed and unskilled workers, thus poor education and unemployment contributed to majority of late presentation.

Regarding to Governorate present the study more than half of them from Assiut Governorate, because Assiut University Hospital and Elramad Hospital are a tertiary medical centers and health literacy in Assiut the most governorate of Upper Egypt which serves a large number of Egyptians from all over Upper Egypt.

According to risk factors of glaucoma Debjit et al. 2012, Onabolu 2014 reported that: The major risk factors for glaucoma include the following: High intraocular pressure, age 50 or older, family history of glaucoma, African Americans, suspicious optic nerve appearance (cupping $>50 \%$ ), thin cornea, high myopia, diabetes, hypertension, eye injury or surgery, history of steroid use, migraine, headaches, sleep apnea.

Smoking is the leading cause of preventable death worldwide. Tobacco use raises the chances of heart and lung disease. It has an impact on your risk for certain vision threatening eye conditions. Many people don't realize that smoking, also affects your eye health, reducing the circulation to the eye and increasing chances of developing cataracts and age-related macular degeneration, in some cases leading to permanent blindness WHO 2011. Other study, there is a strong link between smoking and high blood pressure, cataracts and diabetes, all of which are risk factors for glaucoma. Cigarette smokers greatly raise their chances of developing glaucoma (high eye pressure that damages the optic nerve). This is another leading cause of blindness Bonovasa, et al. 2004 our present findings revealed that, $(69.4 \% \mathrm{n}=694$, no smoking but 30.6 $\mathrm{n}=306$ ) have smoking.

Regard family history, our study represent, $73.0 \% \mathrm{n}=730$, no family history. People with a family history of glaucoma have about six percent chance of developing glaucoma. Glaucoma can be hereditary, although having people in your family with glaucoma does not necessarily mean that you will develop it. These results were similar to Klein 2004 who carried out a study to assess the awareness of the patients suffering primary acute angle closure about glaucoma and health beliefs, and found that $33.3 \%$ of the patients had family history while $78.4 \%$ of the patients did not have family history. Debjit et al. 2012. Family history has consistently been shown to be a risk factor for glaucoma reported that, 
family history may reflect similarity in genes directly related to the development of glaucoma, or may reflect genetic similarity related to IOP or optic nerve anatomy that may influence the development of glaucoma.

Poor awareness of glaucoma is one of the reasons of late appearance of glaucoma. In a study conducted in India, it is reported that lack of education and awareness of glaucoma were major risk factors for late presentation and it might be more important than lack of transportation or access care in terms of regular medical care (Klein 2004).

This study illustrates that the majority of studied sample unaware about glaucoma, rational for result due to a lack of educational resources about glaucoma, lack of time, knowledge and training for nurses to provide patients with accurate information regard glaucoma, good knowledge and practice about prevention, early diagnosis and treatment for glaucoma patients are very important This study consent with Mohamed et al. 2011reported that, only $12 \%$ of young people had satisfactory knowledge about glaucoma. Also, Subhratanu et al. 2015 most of them were unaware of glaucoma in the family, often presenting to the clinic with a much advanced/late stage of the disease. Also, this concur with Mridula et al. 2013 who study about glaucoma awareness and knowledge in a tertiary care hospital in South India and reported that $4.8 \%$ heard about glaucoma and $95.1 \%$ not aware about glaucoma. Eye Diseases Prevalence Research Group 2004 reported that, 50\% or more of those individuals with glaucoma are unaware of their diagnosis; more effort is needed to effectively screen high-risk groups and to educate society about the preventability and consequences of glaucoma. Also Sathy et al. 2009 awareness and knowledge about glaucoma was very low among the urban population of Chennai.

The finding of the present study shows that most of participant answers do not done anything regard self-practice of glaucoma. Patients need health education to increase their awareness about the importance of eye care to reduce the risk of visual impairment. Diagnosis, treatment and care require special attention and knowledge; glaucoma requires lifelong follow up of visual field changes with the goal of preservation of vision, the optic nerve needs to be regularly examined and documented and eye care providers need to keep up- to-date with new methods of glaucoma treatment.

This study illustrated that there is statistically significant difference between educational level and awareness about glaucoma, ( $\mathrm{p}=0.001)$, this agree with Ebru 2011 who study awareness among glaucoma patients and founded that the patients with higher education had better scores $(\mathrm{p}=0.012)$. Also, no significant differences between male gender and lack of glaucoma awareness $p=0.2$, this disagree with some studies from developed countries by Noertjojo et al. 2006 who study awareness of eye diseases and risk factors: identifying needs for health education and promotion in Canada, and found relationship between male gender and lack of glaucoma awareness. On the other hand, these results were disagreed with Onunkwor 2012 who found that there was not any significant difference in glaucoma knowledge across the different educational levels. Health literacy is important for optimizing patient education and improving clinical outcomes. Nurses, physician and media [Social media and television TV] should be used to spread the awareness about the disease (Muir 2010).

\section{Conclusion}

This study provided more insight into the risks factors of glaucoma especially old age, chronic illness. The majority of glaucoma patients complain from unawareness regard glaucoma and show a strong highly statistical significant difference between awareness of studied sample and their education $\mathrm{P}=0.001^{*}$. The study findings stress the need for health education about the glaucoma to effectively prevent blindness due to disease.

\section{Recommendation}

- Design educational program about eye diseases especially glaucoma are need to improve patient knowledge, attitude \& practice regard glaucoma.

- An efficient information, education and communication strategy needs to be designed for early detection and treatment of glaucoma to prevent blindness.

- Social media and TV are another very important, that can play a vital role in bringing the suspects of glaucoma to screening centers and hence an early diagnosis.

- Increasing the awareness about importance of regular eye examinations to detect early health deviation to make early detection, treatment and prevent complications.

Screening for all people above the age 50 years and who suffer from diabetes \& cardiovascular diseases for early detection of visual defect.

\section{References}

[1] Altangerel U, Nallamshetty HS, Uhler T, 2009: Knowledge about glaucoma and barriers to follow-up care in a community glau $\neg$ coma screening program. Can J Ophthalmol.; p p: 44:66-69.

[2] Bonovasa S, Filioussia K, Tsantesa A, \& Peponisb, A., 2004: "Epidemiological association between cigarette smoking and primary open-angle glaucoma: a meta- analysis." Public Health Volume 118 , Issue 4, June, p p: 256-261.

[3] Bourne RR. 2006: Worldwide glaucoma through the looking glass Br J Ophthalmol; pp: 90:253-4

[4] Choe YJ, Hong YJ. 1993: The prevalence of glaucoma in Korean career men. J Korean Ophthalmol Soc.; p p: 34:153-158.

[5] Cook, C. (2009): Glaucoma in Africa: size of the problem and possible solutions. Journal of Glaucoma 18(2): p p: 124-128. http://dx.doi.org/10.1097/IJG.0b013e318189158c.

[6] Dawn A, Freedman, S, \& Enyedi L. 2007: Patients' expectations regard- ing their eye care; interview results. American Journal of Ophthalmology, p p: 136:796-785.

[7] Debjit B., Sampath K.P., Lokesh D., Shravan P. and Dutta A.S.,2012: Glaucoma -A Eye Disorder Its Causes, Risk Factor, Prevention and Medication, the pharma innovation, Vol. 1 No. 1 ,p p: 66- 81 .

[8] Ebru NC, Gulbanu Z, Mehmet Z, Avni M A, Volkan Y, \& Cem Y, 2011: Awareness Among Glaucoma Patients, Glo-Kat;6: p p: 235 238.

[9] Egyptian Society for glaucoma disease, (2011): The treatment and diagnosis of glaucoma, the world's leading cause of irreversible blindness.

[10] El Gilany A H, ElFedawy S, \&Tharwat M. 2012: Causes of blindness and needs of the blind in Mansoura, Egypt. East Mediterr Health J 86-17.17 [PubMed]

[11] Eye Diseases Prevalence Research Group 2004: Prevalence of open-angle glaucoma among adults in the United States. Arch Ophthalmol, p p: 122:532-53

[12] Faal H., 2012: primary open-angle glaucoma. Community Eye Health journal, volum. 25 , issue $79 \& 80$.

[13] Fraser S, Bunce C, \&Wormald R. 2011: Deprivation and late presentation of glaucoma: case control study. [PMC free article] [PubMed]BMJ 322639 p p: -643.643

[14] Glaucoma research foundation (2012): Glaucoma risk factors and prevention, http://www.ahaf.org/glaucoma/about/risk.html.

[15] Gordon, M.O. \& Beiser, J. A., 2002: The ocular hypertension treatment study: baseline factors that predict the onset of primary open-angle glaucomaArch. Ophthalmol, 714-720; discussion p p 829-830.

[16] Grehn F and Stamper R (2009): The Epidemiology of Glaucoma, chapter 2. p p: 443-449.

[17] Hong C, Joo JH, Shin KH, \& Song KY. 1987: Clinical study of Korean glaucomatous patients. Korean J Ophthalmol. ; p p: 1:41-46.

[18] Iwase A, Suzuki Y, \& Araie M, 2004: The prevalence of primary open-angle glaucoma in Japanese: the Tajimi Study. Ophthalmology; p p: 111:1641-1648.

[19] Klein BE, Klein R, \&Lee KE, 2004: Heritability of risk fac- tors for primary open-angle glaucoma: the Beaver Dam Eye study. Invest Ophthalmol Vis Sci p p: 45:59-62.

[20] Krishnaiah, S Kovai, V, Srinivas, M Shamanna. R, Rao, and Thomas. R (2009): Awareness of glaucoma in the rural population of 
Southern India, Community Ophthalmology, volume53, issue3, p p: 205-208.

[21] Marion M. \& Tumully R. 2007: Prevalence and incidence statistics for glaucoma in Northern Africa. American Journal of Nursing, p p: 83:752-756.

[22] Miglior, S., Fraser S, Bunce C, \& Wormald R. 2011: Deprivation and late presentation of glaucoma: case control study. [PMC free article] [PubMed]BMJ 322.639-643.643.

[23] Mohamed E.A., Bayoumi O.R and Draz S.F. 2011: Impact of an educational program on knowledge, beliefs, practices and expectations about care among adolescent glaucoma patients in Cairo. Eastern Mediterranean Health Journal Vol. 17 No. 12. p p: 960 968.

[24] Mridula Prabhu, Shankargouda H Patil, Pravin Chandra R \&Kangokar, 2013: Glaucoma awareness and knowledge in a tertiary care hospital in a tier-2 city in South India Year: 2013 | Volume: 40 | Issue: 1 | pp: 3-8 journal of scientific society.

[25] Muir KW \&Lee PP. 2010: Health literacy and ophthalmic patient education. Surv Ophthalmol. P P: 55:454-459.

[26] National Institute for Health and Care Excellence 2009: Glaucoma: diagnosis and management of chronic open angle glaucoma and ocular hypertension. April. http://www.nice.org.uk/nicemedia/ live/12145/43887/43887.pdf (accessed 15 Jul 2013).

[27] Neuberger J. 2000: The educated patient with glaucoma: new challenges for the medical profession. Journal of Internal Medicine, $\mathrm{p} \mathrm{p}$ : 74:6-10. 8.

[28] Nilforushan, Naveed; Yadgari M, Falavarjani KG, Fraser S, Bunce C, \&Wormald R. 2011: Deprivation and late presentation of glaucoma: case control study. [PMC free article] [PubMed].BMJ p p: 322.635-643.641.

[29] Noertjojo K, Maberley D, Bassett K \& Courtright P, 2006: Awareness of eye diseases and risk factors: identifying needs for health education and promotion in Canada.Can J Ophthalmol, p p: 41, 617-23.

[30] Onabolu OO \& Bodunde OT. 2014: Awareness and knowledge of glaucoma among primary care givers in a developing country. Ann Trop Med Public Health [serial online] [cited 2016 Jan 13]; p p: 5-8. Available from: http://www.atmph.org/text.asp?2014/7/1/5/144997.

[31] Onunkwor, C. and Monareng, L. V. (2012): glaucoma knowledge of patients in Abuja, Nigeria Africa journal of nursing \& midwifery; vol. 14 issue $1, \mathrm{p} 3$.

[32] Pascolini D. \& Mariotti SP. 2012: Global estimates of visual impairment: 2010.Br J Ophthalmol; p p: 96:614-618.

[33] Philippin H. Shah P. and Burton M., 2012: detailed assessment of an adult glaucoma patient, Community Eye Health journal; p p 25(79-80): 50-53.

[34] Quigley HA. \& Broman AT. 2006: The number of people with glaucoma worldwide in 2010and 2020. Br J Ophthalmol; p p: 90:262-267.

[35] Sathy amangalam Rv, Paul PG,George R. Baskaran M,Hemamalini A, \& Madan RV.2009: "determinants of glacuma awareness and kowlegde in urban chemnai .indian $\mathrm{J}$ opththamology , 57: p p: 355 360.

[36] Subhratanu Chakrabarty, K. Kanthamani, Narendra P Datti, Ashwini Ravindra Mahajan, \& Rashmi NR,2015: glaucoma - a socio economic perspective , International Journal of Biological \& Pharmaceutical Research. 6 (1) p p: 1-5.

[37] Tenkir, 2010: Glaucoma awareness among people attending ophthalmic outreach services in Southwestern Ethiopia BMC Ophthalmology, pp: 10:17.

[38] Tsai T, Robin AL, \& Smith JP. 2007: An evaluation of how glaucoma pav - tients use topical medications: a pilot study. Transactions of the American Ophthalmological Society, p p: 105:29-35. 9.

[39] World Health Organization (WHO) 2011: Report on the global tobacco epidemic, Warning about the dangers of tobacco, p p: 632 640 . 